\title{
Differential Activity of Plasma and Vacuolar Membrane Transporters Contributes to Genotypic Differences in Salinity Tolerance in a Halophyte Species, Chenopodium quinoa
}

Edgar Bonales-Alatorre ${ }^{1,2}$, Igor Pottosin ${ }^{2}$, Lana Shabala ${ }^{1}$, Zhong-Hua Chen ${ }^{3}$, Fanrong Zeng ${ }^{1,4}$, Sven-Erik Jacobsen ${ }^{5}$ and Sergey Shabala ${ }^{1, *}$

1 School of Agricultural Science and Tasmanian Institute for Agriculture, University of Tasmania, Private Bag 54, Hobart, TAS 7001, Australia; E-Mails: edgarbonales@hotmail.com (E.B.-A.); L.Shabala@utas.edu.au (L.S.); Fanrong.Zeng@utas.edu.au (F.Z.)

2 University Centre for Biomedical Research, University of Colima, 28045 Colima, Mexico; E-Mail: pottosin@mail.ru

3 School of Science and Health, University of Western Sydney, Richmond, NSW 2753, Australia; E-Mail: Z.Chen@uws.edu.au

4 College of Agriculture and Biotechnology, Zhejiang University, Hangzhou 310058, China

5 Department of Plant and Environmental Sciences, Faculty of Science, University of Copenhagen, Højbakkegaard Allé 13, 2630 Taastrup, Denmark; E-Mail: seja@life.ku.dk

* Author to whom correspondence should be addressed; E-Mail: Sergey.Shabala@utas.edu.au; Tel.: +61-3-6226-7539; Fax: +61-3-6226-2642.

Received: 22 February 2013; in revised form: 13 April 2013 / Accepted: 15 April 2013 / Published: 29 April 2013

Abstract: Halophytes species can be used as a highly convenient model system to reveal key ionic and molecular mechanisms that confer salinity tolerance in plants. Earlier, we reported that quinoa (Chenopodium quinoa Willd.), a facultative C3 halophyte species, can efficiently control the activity of slow (SV) and fast (FV) tonoplast channels to match specific growth conditions by ensuring that most of accumulated $\mathrm{Na}^{+}$is safely locked in the vacuole (Bonales-Alatorre et al. (2013) Plant Physiology). This work extends these finding by comparing the properties of tonoplast FV and SV channels in two quinoa genotypes contrasting in their salinity tolerance. The work is complemented by studies of the kinetics of net ion fluxes across the plasma membrane of quinoa leaf mesophyll tissue. Our results suggest that multiple mechanisms contribute towards genotypic differences in salinity tolerance in quinoa. These include: (i) a higher rate of $\mathrm{Na}^{+}$exclusion from leaf mesophyll; (ii) maintenance of low cytosolic $\mathrm{Na}^{+}$levels; (iii) better $\mathrm{K}^{+}$retention in the leaf 
mesophyll; (iv) a high rate of $\mathrm{H}^{+}$pumping, which increases the ability of mesophyll cells to restore their membrane potential; and (v) the ability to reduce the activity of SV and FV channels under saline conditions. These mechanisms appear to be highly orchestrated, thus enabling the remarkable overall salinity tolerance of quinoa species.

Keywords: sodium exclusion; vacuolar sequestration; potassium retention; mesophyll; cytosol; $\mathrm{H}^{+}$-ATPase; SOS1 exchanger

\section{Introduction}

The physiological and genetic complexity of salt tolerance significantly handicaps progress in breeding crops for this important trait [1]. Nonetheless, about $1 \%$ of land plants are not only capable of surviving under highly saline conditions, but actually benefit from the presence of substantial quantities of salt in the growth media [2,3]. For most of these species, optimal growth is achieved at salinity levels ranging between 150 and $200 \mathrm{mM}$ (e.g., Salicornia [4]; Atriplex [5]; quinoa [6]), while for others, the optimum salt level in the media can be as high as seawater, i.e., $\sim 500 \mathrm{mM} \mathrm{NaCl}$ (Sarcocornia fruticose and Arthrocnemum macrostachyum; [7]). This is in stark contrast to glycophytes; most wheat varieties will show little if any yield at $150-200 \mathrm{mM} \mathrm{NaCl}$ and not a single rice genotype will be able to survive under such salinity levels [8,9]. So, how do these halophyte species flourish under saline conditions and how can we make wheat and rice as tolerant as halophytes?

It is generally accepted that the hallmark of salinity tolerance in halophytes is efficient vacuolar $\mathrm{Na}^{+}$ sequestration [10,11]. As such, halophytes are classified as $\mathrm{Na}^{+}$includers, while most crops adopt a $\mathrm{Na}^{+}$exclusion strategy [12,13]. However, as commented by many authors $[3,11]$, there is no a clear-cut line between halophytes and glycophytes. Salt tolerance in plants is not an either or condition; it represents a continuum of degrees of tolerance to salinity. Salt-tolerant glycophyte species, such as barley, have successfully implemented key physiological mechanisms that confer salinity tolerances in halophytes. These include high tissue tolerance, efficient control of xylem $\mathrm{Na}^{+}$loading and the use of inorganic ions for osmotic adjustment [14-16]. Indeed, it appears that there is nothing unique to halophytes that is not present in glycophytes. The major difference is how efficiently these mechanisms are implemented by the two plant groups [3].

Over the last few years, the research focus of our laboratories has been on quinoa (Chenopodium quinoa Willd.), a C3 facultative halophyte species of high nutritional and agronomical value [17,18]. Despite showing remarkable salinity tolerance [6,19], quinoa genotypes nevertheless display significant variability in agronomical and physiological responses when grown under saline conditions [20]. The physiological basis for this genetic variability in salinity tolerance in quinoa, as well as in other halophytic species, is not fully understood. Our very recent study involving 14 quinoa varieties revealed that, despite all being halophytes, quinoa genotypes are clustered into two distinct groups- "includers" and "excluders" - according to their ability to accumulate $\mathrm{Na}^{+}$in the shoot [21]. Previously, such opposite strategies have been described mainly for highly contrasting species (e.g., wheat and barley) or when comparing adaptive mechanisms between glycophytes and halophytes [11]. Now, it appears 
that even within the same species of a halophyte, multiple strategies are used to deal with salinity. The reasons for this are unclear, as are the mechanisms involved. Can this duality in strategies of handling $\mathrm{Na}^{+}$accumulation in the shoot be related to differential tissue tolerance among quinoa varieties or is it associated with differences in the ability to effectively sequester $\mathrm{Na}^{+}$to the vacuole?

Efficient vacuolar sequestration of cytotoxic $\mathrm{Na}^{+}$has always been considered as one of the most, if not the most, prominent feature of halophytes $[10,11,22]$. This process requires two complementary components: (1) active $\mathrm{Na}^{+}$pumping into the vacuole against the electrochemical gradient; and (2) preventing $\mathrm{Na}^{+}$from leaking back into cytosol [23]. While the molecular basis of the first component is well defined and is attributed to activity of tonoplast $\mathrm{Na}^{+} / \mathrm{H}^{+}$antiporters [22,24], the mechanisms responsible for preventing $\mathrm{Na}^{+}$from leaking back into the cytosol remain elusive. Recently, we showed that the properties of $\mathrm{Na}^{+}$-permeable fast- (FV) and slow- (SV) vacuolar channels differed dramatically between young and old quinoa leaves grown under saline conditions [25]. The SV channel is permeable to both mono- and di-valent cations and is activated by cytosolic $\mathrm{Ca}^{2+}$ and positive vacuolar voltage, while the FV channel is permeable for monovalent cations only and is inhibited by divalent cations ([25] and references within). We showed that at physiologically relevant tonoplast potentials that favour $\mathrm{Na}^{+}$leak from the vacuole (e.g., 0 to $20 \mathrm{mV}$ ), most FV channels were functionally inactive in salt-grown old leaves, while FV conductance in young leaves grown under similar conditions was at least two-fold higher. This mirrors the amount of $\mathrm{Na}^{+}$accumulated in mesophyll cells. Also, the number of active SV channels in young leaves (containing less $\mathrm{Na}^{+}$) exceeded the number for old leaves by seven-fold under saline conditions. Most of the SV channels were closed at physiologically relevant tonoplast potentials in salt-grown old leaves, while in young leaves, SV currents were substantial [25]. It was suggested that quinoa plants are able to control the activity of SV and FV tonoplast channels to match the specific growth conditions by ensuring that most of accumulated $\mathrm{Na}^{+}$is safely locked in the vacuole of old leaves.

This work extends the above findings by comparing the properties of tonoplast FV and SV channels in two quinoa genotypes contrasting in their salinity tolerance. The results are complemented by studies of the kinetics of net ion fluxes across the plasma membrane of quinoa leaf mesophyll tissue. Taken together, our results suggest that multiple and highly orchestrated ionic mechanisms contribute to salinity tolerance in quinoa and this determines the genotypic variability in this trait in the Chenopodium family.

\section{Results}

Four weeks of $400 \mathrm{mM} \mathrm{NaCl}$ treatment significantly reduced growth in the sensitive genotype Q5206, but had no significant (at $p<0.05$ ) impact on the performance in the tolerant genotype Q16 (Figure 1). Salt-grown Q5206 plants looked stunted (Figure 1A) and their biomass was only at $\sim 50 \%$ of the control (Figure 1B,C). No such reduction was found in the Q16 genotype (Figure 1). These results are therefore consistent with our previous findings that report a superior salinity tolerance in Q16 [20,21], paving the foundation for their use as contrasting genetic material in this work. 
Figure 1. Genotypic differences in salinity stress tolerance in quinoa. Plants were grown under optimal (50 mM NaCl; defined as control) and saline (400 $\mathrm{mM} \mathrm{NaCl})$ conditions for four weeks. (A) Visual difference in genotypic responses to salinity; (B) shoot fresh weight (FW) of quinoa plants grown under control and saline conditions; (C) shoot FW of salt-grown plants expressed as $\%$ of control. Mean \pm SE $(n=6)$. Data labelled with asterisk are significant at $p<0.05$.
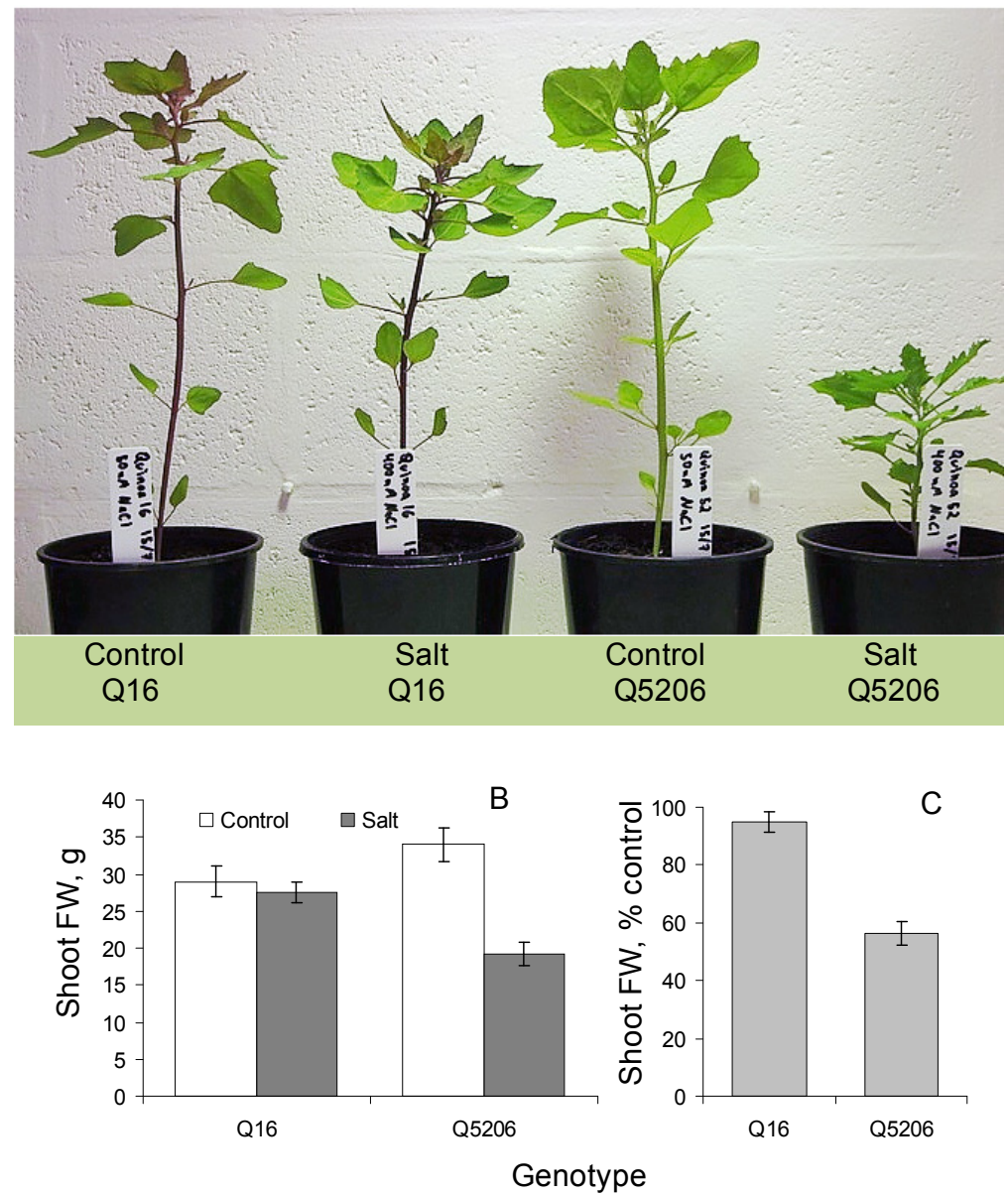

Prolonged salinity treatments can result in substantially raised xylem $\mathrm{Na}^{+}$contents, typically reaching a range of 50 to $100 \mathrm{mM}$ (reviewed in [3]). The accumulation of such high $\mathrm{Na}^{+}$ concentrations in the leaf apoplast may affect mesophyll cell ionic homeostasis, with major implications for metabolic performance. This issue was addressed in this work by measuring the kinetics of net ion flux responses to acute salinity treatment $(100 \mathrm{mM} \mathrm{NaCl}$ added directly to the leaf mesophyll; Figure 2). A significant genotypic difference was found in net ion flux responses of quinoa mesophyll to salinity for all the measured ions.

Acute salt stress caused an immediate uptake of $\mathrm{Na}^{+}$into the leaf mesophyll; an uptake that was two-fold higher in the salt-sensitive Q5206 genotype than the tolerant genotype Q16 (significant at $p<0.05$; Figure 2A). This net $\mathrm{Na}^{+}$uptake was short lived, and $20 \mathrm{~min}$ after stress onset, both genotypes switched to net $\mathrm{Na}^{+}$efflux (pumping $\mathrm{Na}^{+}$out; Figure $2 \mathrm{~B}$ ). The rate of $\mathrm{Na}^{+}$pumping was three-fold higher in the tolerant genotype Q16 (Figure 2B; significant at $p<0.05$ ). Two major propositions can be made based on these observations: (i) an active $\mathrm{Na}^{+}$efflux system is present at the plasma membrane of leaf mesophyll cells (e.g., a functional homologue of the Arabidopsis SOS1 
$\mathrm{Na}^{+} / \mathrm{H}^{+}$exchanger; [26]) and (ii) the activity of this active efflux system correlates with salinity tolerance in quinoa.

Similar to our previous observation from other species [27-29], salinity treatment resulted in a massive $\mathrm{K}^{+}$leak from the leaf mesophyll (Figure 2C). In the tolerant genotype Q16, this leak was much less ( two-fold) than in the sensitive Q5206 genotype (significant at $p<0.05$ ). Taken together, the better $\mathrm{K}^{+}$retention (Figure $2 \mathrm{C}$ ) and better $\mathrm{Na}^{+}$exclusion (Figure $2 \mathrm{~B}$ ) ability of the genotype Q16 would enable a more optimal cytosolic $\mathrm{K}^{+} / \mathrm{Na}^{+}$in the cytosol of this genotype.

Figure 2. Net ion flux kinetics measured from leaf mesophyll tissue in response to acute $100 \mathrm{mM} \mathrm{NaCl}$ treatment (added at the time indicated by an arrow). Two quinoa varieties contrasting in their salinity tolerance (Q16, tolerant; Q5206, sensitive) were used. $(\mathbf{A}, \mathbf{B})$ net $\mathrm{Na}^{+}$flux resolved at initial (first $\left.5 \mathrm{~min}\right)$ and later $(1 \mathrm{~h}$ after stress onset) stages of stress response. (C,D) net $\mathrm{K}^{+}$and $\mathrm{H}^{+}$fluxes, respectively. Mean $\pm \mathrm{SE}(n=6-8)$. The sign convention is "influx positive".

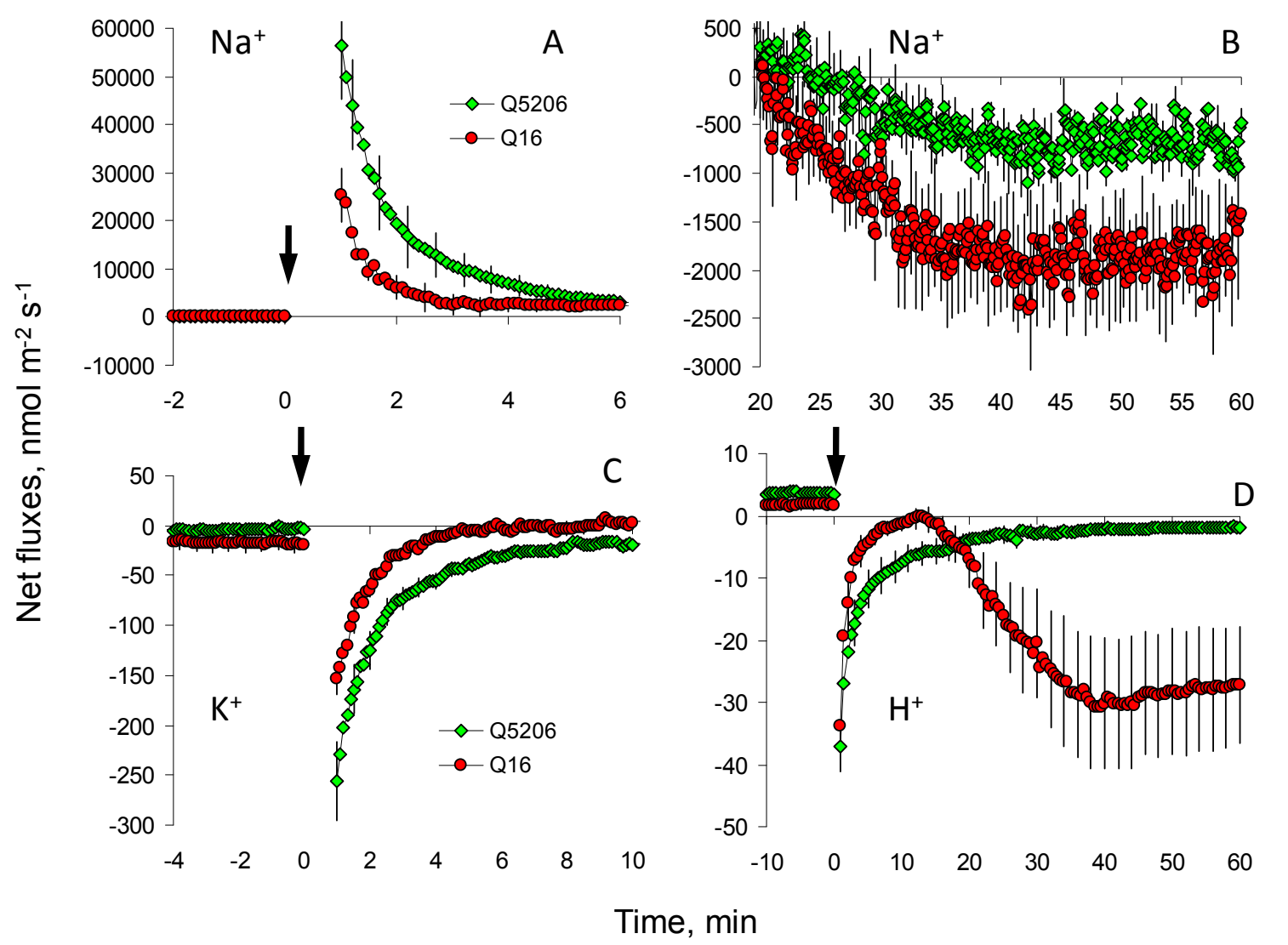

In other species, such as barley [14] and lucerne [30], a better $\mathrm{K}^{+}$retention ability in tolerant varieties is always attributed to the maintenance of a more negative membrane potential under saline conditions; a trait conferred by higher $\mathrm{H}^{+}$-ATPase activity [31]. Here, we report indirect evidence that differential $\mathrm{H}^{+}$-ATPase activity may also be the case for the observed genotypic differences in salinity stress tolerance in quinoa. Indeed, while in the sensitive Q5206 variety, NaCl-induced stimulation of $\mathrm{H}^{+}$efflux was transient and lasted for only a few minutes; in the tolerant Q16 genotype, a massive $\mathrm{H}^{+}$ efflux was measured $1 \mathrm{~h}$ after stress onset. Similar to reports on other species [27], this NaCl-induced $\mathrm{H}^{+}$efflux was vanadate-sensitive (data not shown), suggesting that it is mediated by the plasma 
membrane $\mathrm{H}^{+}$-ATPase. This $\mathrm{H}^{+}$efflux would be expected to restore (an otherwise depolarised) cell membrane potential, which would explain the better $\mathrm{K}^{+}$retention in Q16 (Figure 2C), assuming that, similar to many other species [32], $\mathrm{K}^{+}$leak in quinoa is mediated by depolarisation-activated outward-rectifying $\mathrm{K}^{+}$channels (GORK in Arabidopsis; [33]).

The predicted genotypic difference in cytosolic $\mathrm{Na}^{+}$accumulation based on MIFE $\mathrm{Na}^{+}$flux data (Figure 2A,B) was further investigated in planta using CoroNa Green fluorescent dye (Figure 3). This revealed that cytosolic $\mathrm{Na}^{+}$levels were substantially lower in the tolerant Q16 genotype (two-fold; significant at $p<0.05$ ) (Figure 3E). The same two-fold difference was also found for vacuolar $\mathrm{Na}^{+}$concentrations (Figure $3 \mathrm{~F}$ ). These observations are consistent with our previous reports of Q16 being an "excluder", accumulating less $\mathrm{Na}^{+}$in the shoot compared to Q5206 [21].

As noted in the Introduction, efficient control of tonoplast FV and SV channels is essential for vacuolar $\mathrm{Na}^{+}$sequestration. We therefore compared the properties of $\mathrm{FV}$ and $\mathrm{SV}$ currents in isolated mesophyll vacuoles of two quinoa varieties contrasting in their salinity tolerance.

Figure 3. $\mathrm{Na}^{+}$accumulation in quinoa leaves, visualised by confocal imaging using CoroNa Green fluorescent dye. One (of six to 10) representative images is shown for each treatment. The scale bar size is $50 \mu \mathrm{m}$. (A) Q16 leaf in control; (B) Q16 leaf grown at $400 \mathrm{mM} \mathrm{NaCl}$; (C) Q5206 leaf in control; (D) Q5206 leaf at $400 \mathrm{mM} \mathrm{NaCl}$. Plants grown under saline conditions accumulate more $\mathrm{Na}^{+}$in leaf mesophyll cells, as evident by more intensive green colour. (E,F) cytosolic (E) and vacuolar (F) $\mathrm{Na}^{+}$concentrations in quinoa mesophyll cells quantified from confocal CoroNa Green data (arbitrary units). Mean $\pm \mathrm{SE}$ $(n=40)$. Different lowercase letters indicate the significance level at $p<0.05$.

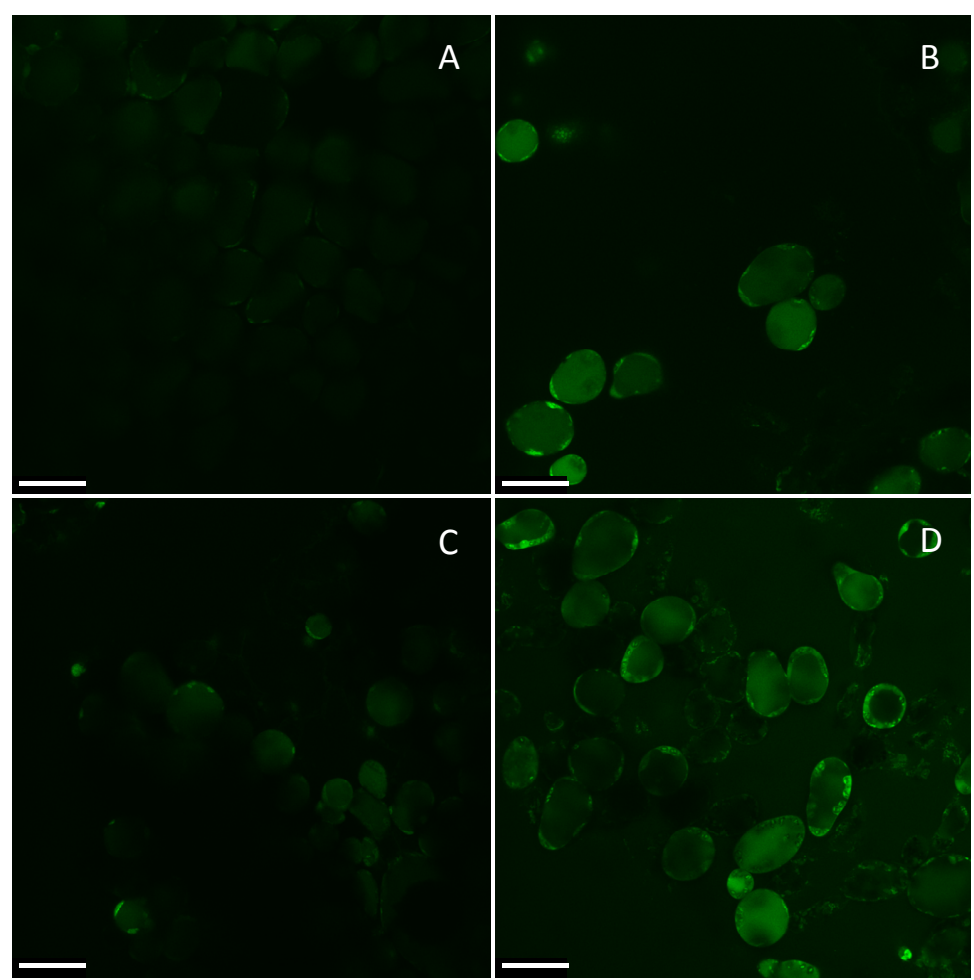


Figure 3. Cont.
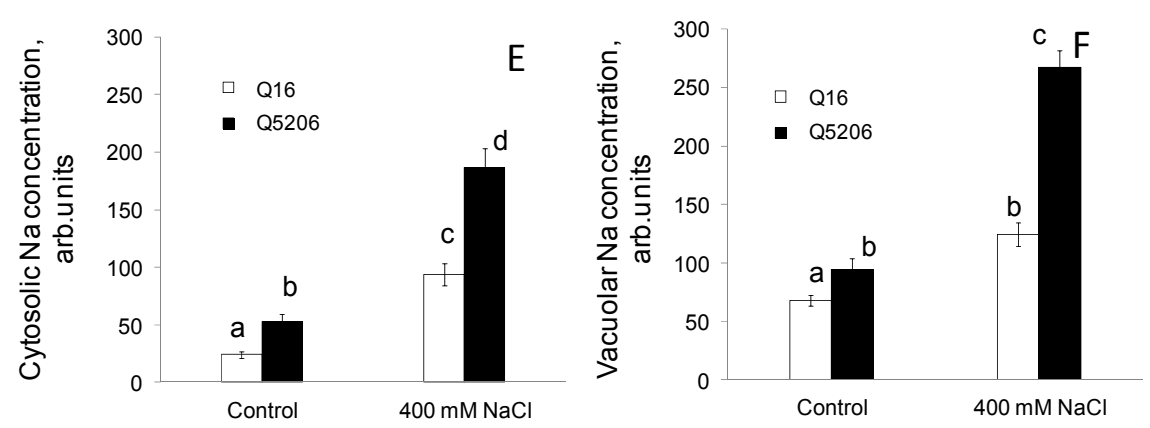

Tonoplast conductance is dominated by instantaneously activated FV currents at zero free concentrations of divalent cations $\left(\mathrm{Ca}^{2+}\right.$ and $\left.\mathrm{Mg}^{2+}\right)$ on both sides of the membrane. Recordings immediately after breaking into the whole vacuole configuration revealed instantaneous currents with a marked outward rectification (larger currents evoked by cytosol-positive voltages, Figure 4). This current remained stable over a period of time (typically up to 15-20 min), before suddenly growing to reach a new stable state (illustrated by comparing panels $\mathrm{A}$ and $\mathrm{B}$ ). This phenomenon is known as a run-up and has previously been described for FV currents in other plant systems [34]. Regardless of the nature of the cation used in a pipette (e.g., $\mathrm{K}^{+} v s . \mathrm{Na}^{+}$), $\mathrm{FV}$ currents were about the same (Figure 4) and showed the same run-up patterns. This is consistent with previous reports of FV channels being almost equally selective for $\mathrm{Na}^{+}$and $\mathrm{K}^{+}[25,35]$ and suggests that either ion can be used to study the properties of FV channels in quinoa.

Figure 4. Typical whole vacuole recordings of fast-activating vacuolar (FV) currents from the Q5206 genotype, illustrating a run-up phenomenon in patch-clamp measurements. (A,B) typical FV current recordings in a symmetrical $100 \mathrm{mM} \mathrm{KCl}$ solution from small $(\mathrm{C} \sim 3 \mathrm{pF})$ quinoa tonoplast vesicles, isolated from a large central vacuole, shortly (1 min; defined as initial; panel $\mathbf{A}$ ) and $30 \mathrm{~min}$ after obtaining a whole vacuole configuration (defined as final; panel B); (C,D) as above, for $100 \mathrm{mM} \mathrm{NaCl}$ in the pipette. One (of six to 10 vacuoles) typical recording is shown for each case.

Q5206 SENSITIVE

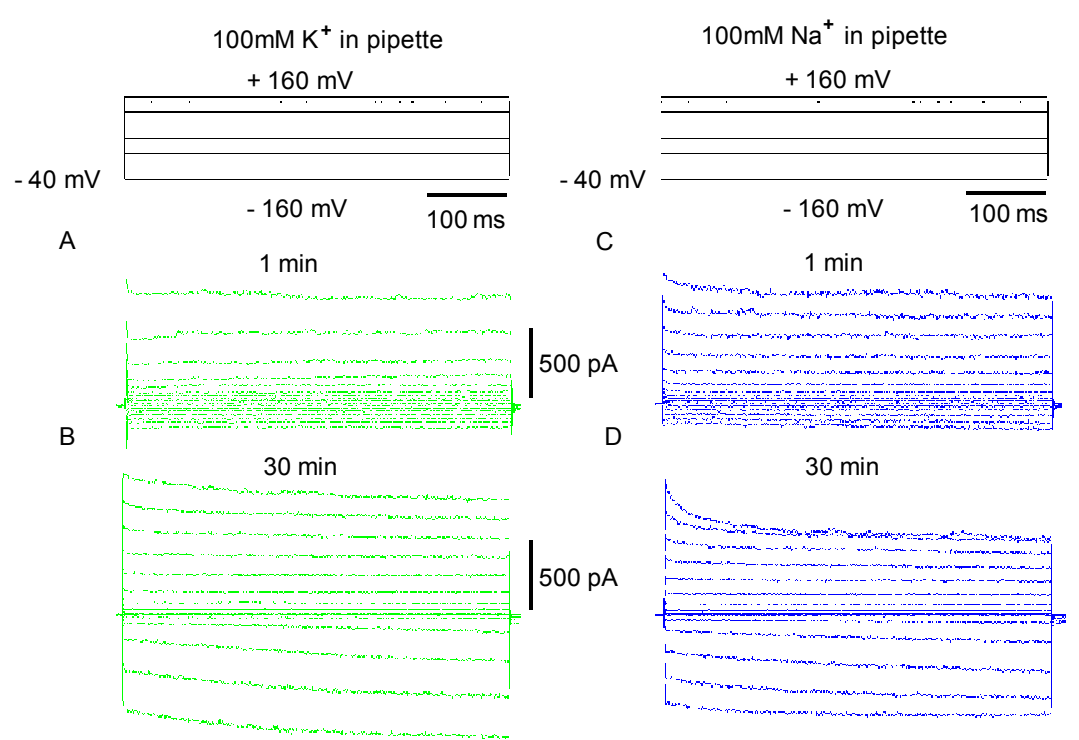


When the initial FV currents were compared in the two varieties, the current density was substantially smaller in the tolerant Q16 genotype (Figure 5A,C, respectively). No noticeable effects of the growth conditions (e.g., control vs. salt-grown) were found in either genotype (Figure 5A-D, respectively).

Figure 5. A comparison of the magnitude of the initial fast-activating (FV) currents, measured in the whole vacuole mode in salt-tolerant Q16 and salt-sensitive Q5206 quinoa genotypes grown under control $(\mathbf{A}, \mathbf{C})$ and high $(400 \mathrm{mM})$ salt $(\mathbf{B}, \mathbf{D})$ conditions. One typical recording is shown for each case (five to eight vacuoles for each genotype). Whole vacuole capacitance was $\sim 3 \mathrm{pF}$ in all cases.

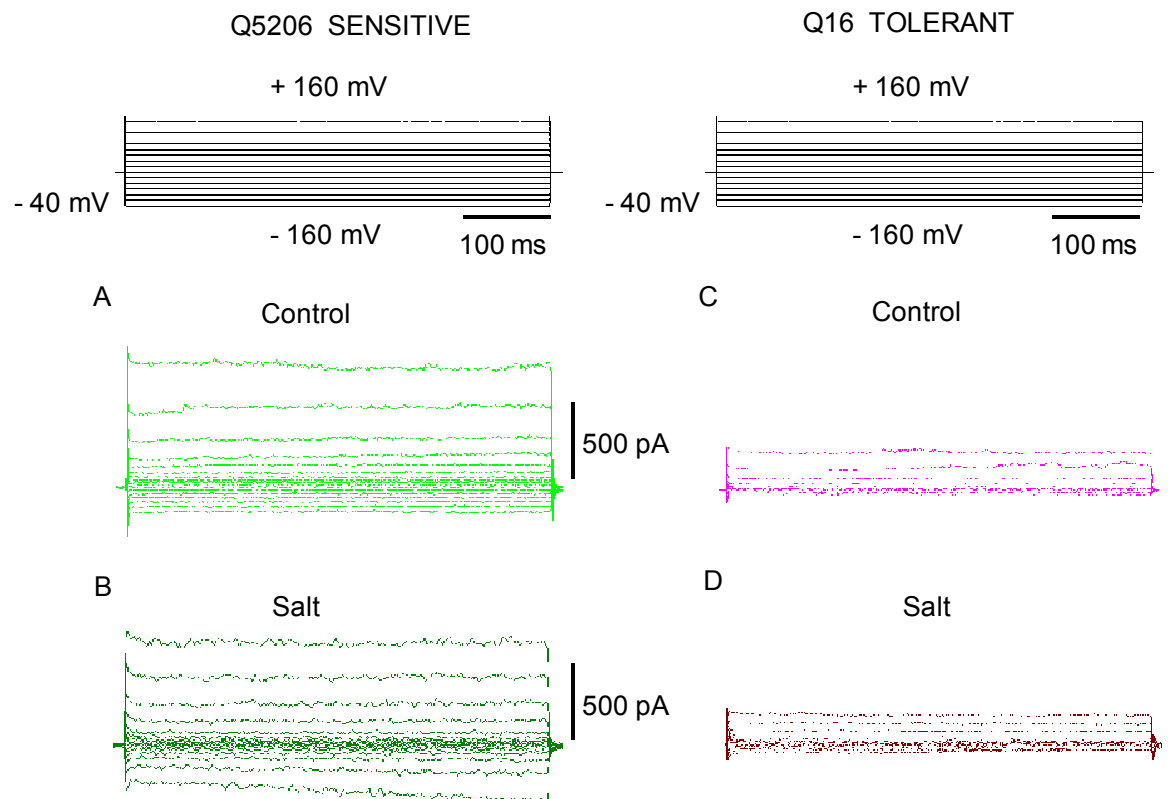

The above observations are further supported by the statistical information reported in Figure 6 . A semi-logarithmic plot of conductance vs. voltage $(\mathrm{G} / \mathrm{V})$ was used to visualise FV channel voltage-dependent activity (Figure 6A,B). Of specific interest are FV conductances at physiological (near-zero) tonoplast potentials, presented separately in Figure 6C. Within this range $(-20$ to $+20 \mathrm{mV})$, FV conductance in the salt-sensitive Q5206 genotype was three- to five-fold higher than the salt-tolerant Q16. Nonetheless, the growth conditions had no significant $(p<0.05)$ observable effect (open and closed symbols in Figure 6A,B).

The effect of the growth conditions was very pronounced though when FV currents were analysed in their final state (e.g., 30 min after vacuole perfusion and seal formation). Salt grown plants (treated with $400 \mathrm{mM} \mathrm{NaCl}$ for four weeks) showed greatly reduced FV currents (Figure 7). While this phenomenon was observed in both genotypes (Figure 7), it was more pronounced in the salt-sensitive Q5206 genotype (4.9 \pm 0.2-fold in Q5206 vs. $2.5 \pm 0.3$-fold in Q16, respectively, within the physiologically relevant range of tonoplast potentials; Figure 8 ). 
Figure 6. FV currents are smaller in vacuoles isolated from the salt tolerant Q16 genotype. $(\mathbf{A}, \mathbf{B})$ Whole vacuolar FV conductance was evaluated in salt-sensitive (Q5206; panel A) and salt-tolerant (Q16; panel B) genotypes by taking the first derivative of the whole vacuole I/V relationship, measured immediately after achieving the whole vacuole configuration. Vacuoles were isolated from leaves of quinoa plants grown in the presence of $50 \mathrm{mM} \mathrm{NaCl}$ (control) or saline $(400 \mathrm{mM} \mathrm{NaCl}$ for four weeks, salt). Data are means \pm SE. Solid lines are best fits to a three-state ("open1-closed-open2") model [36]. Pipette and bath solutions contained $100 \mathrm{mM} \mathrm{KCl}$; (C) Same data as $\mathbf{A}, \mathbf{B}$, but only the points within the physiological tonoplast potential range $( \pm 20 \mathrm{mV})$ are considered.
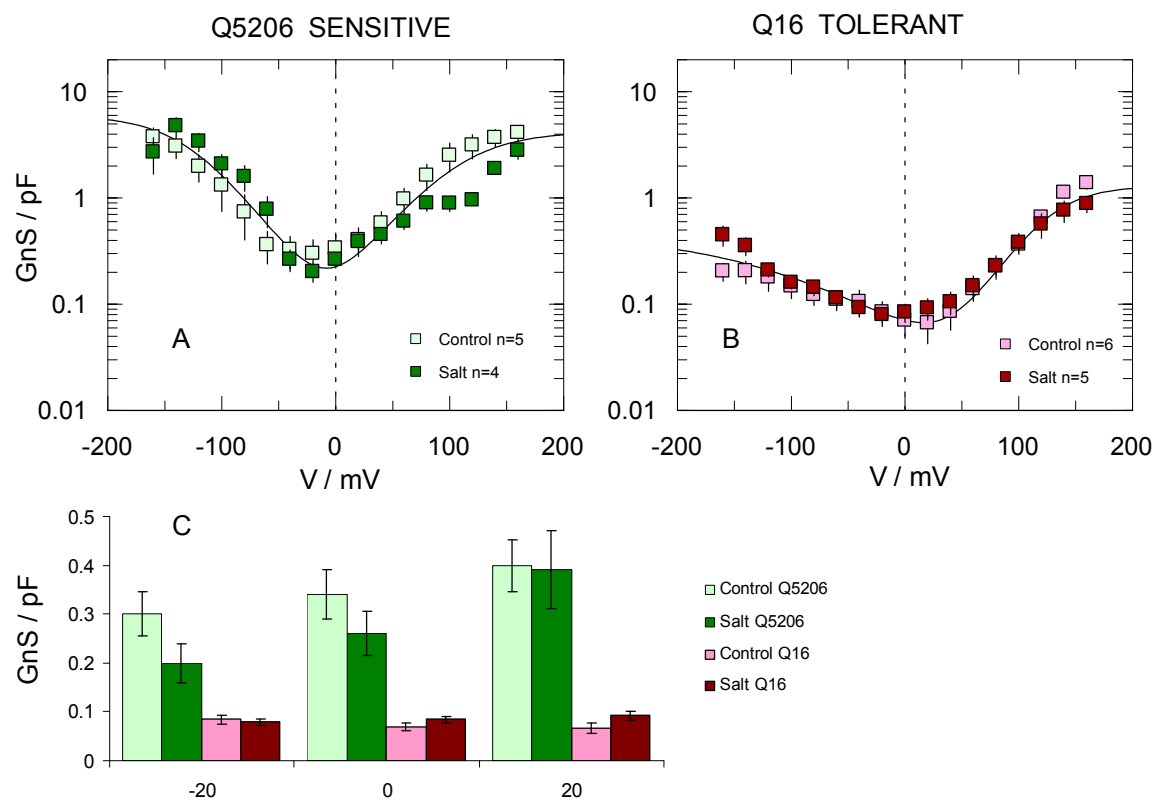

Figure 7. A comparison of the amplitude of the final steady-state whole-vacuole fast-activating (FV) currents between salt tolerant Q16 and salt-sensitive Q5206 genotypes, grown under control $(\mathbf{A}, \mathbf{C})$ and high $(400 \mathrm{mM})$ salt $(\mathbf{B}, \mathbf{D})$ conditions. One typical recording is shown for each case (obtained from five to eight vacuoles). Vacuolar vesicles with a capacitance $\sim 3 \mathrm{pF}$ were chosen for this illustration.

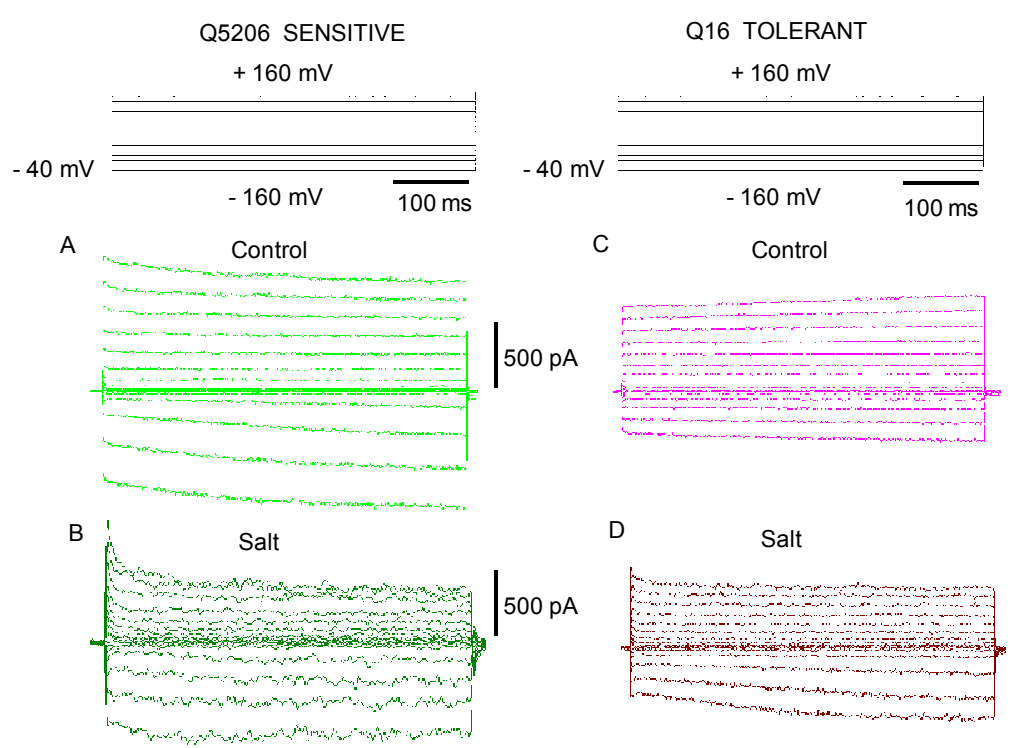


In the final state, the $\mathrm{I} / \mathrm{V}$ curve of the FV current was $\mathrm{N}$-shaped, presenting a high resistance (low conductance) region of $c a .-40 \mathrm{mV}$ under symmetrical $100 \mathrm{mM} \mathrm{KCl}$ conditions. In contrast, at high potentials of either sign, the conductance steeply increased (Figure 8A,B). Vacuolar FV currents were 2-3-fold higher in the salt-sensitive Q5206 genotype than in the salt-tolerant Q16, within a physiologically relevant range of tonoplast potentials (Figure 8C).

Figure 8. Salinity reduces the final vacuolar FV currents in quinoa. $(\mathbf{A}, \mathbf{B})$ Whole vacuolar FV conductance was evaluated in salt-sensitive (Q5206; panel A) and salt-tolerant (Q16; panel B) varieties by taking the first derivative of the whole vacuole $\mathrm{I} / \mathrm{V}$ relationship, measured $30 \mathrm{~min}$ after achieving the whole vacuole configuration. Growth conditions, pipette ion composition and data analysis are the same as in Figure 6; (C) Same data as $\mathbf{A}, \mathbf{B}$, but only the points within the physiological tonoplast potential range $( \pm 20 \mathrm{mV})$ are shown.
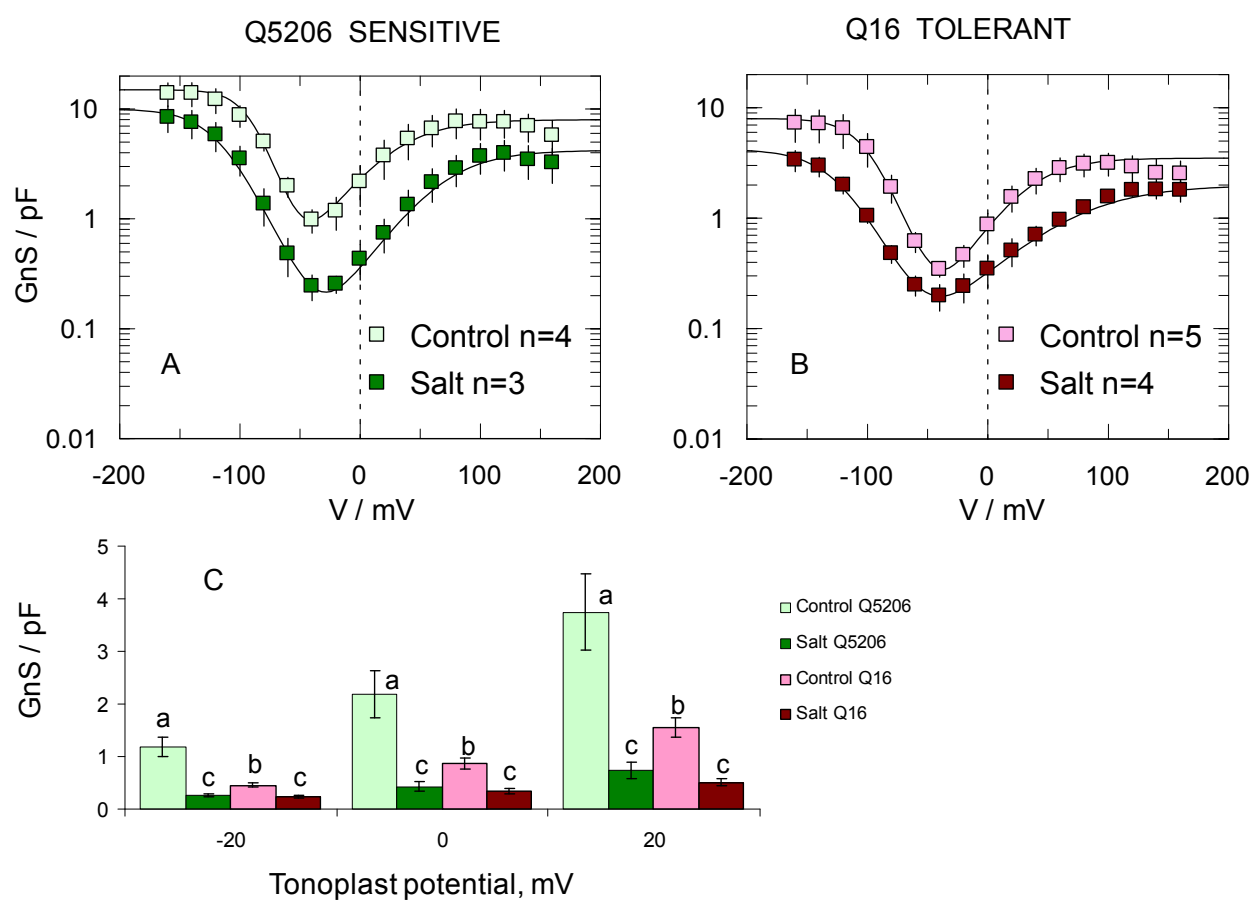

Another possible pathway mediating $\mathrm{Na}^{+}$leak into the cytosol could be via SV channels [37]. In quinoa, these channels were shown to be slightly more permeable for $\mathrm{Na}^{+}$than $\mathrm{K}^{+}\left(\mathrm{P}_{\mathrm{Na} / \mathrm{K}}=1.6-1.8\right)$. Keeping in mind that high vacuolar $\mathrm{Na}^{+}$decreases the threshold for SV channel voltage activation [38], an even tighter control of SV channels is required under saline conditions to avoid their mediation of $\mathrm{Na}^{+}$leakage.

Figure 9 compares the activity of SV channels in the mesophyll tonoplast of salt-sensitive (Q5206) and salt-tolerant (Q16) quinoa varieties. The original records (Figure 9A) show that in the salt-sensitive genotype, the threshold for the activation is quite low (at $-60 \mathrm{mV}$ ). However, it switches to $-20 \mathrm{mV}$ in salt-grown plants, these also displaying a slower SV current activation. A shift of voltage dependence, induced by salt, implies a 10-fold decrease of mean activity of SV channels at physiologically attainable transtonoplast potentials $[(-20)-0 \mathrm{mV}$, Figure $9 \mathrm{~B}]$. Regarding the salt-tolerant Q16, under control conditions, the SV activation curve for this genotype already resembles that for 
salinized Q5206 plants, while for salt-grown Q16 plants, only a moderate shift of the threshold for the SV voltage activation was observed (Figure 9B).

Figure 9. Effects of salinity on the activity of SV channels in mesophyll vacuoles from two contrasting quinoa genotypes. (A) Typical records of the SV channel activation in response to positive voltage steps. Inset (same colour coding) shows parts of the same recordings (only the traces between -60 to $+20 \mathrm{mV}$ ) followed by a step to $-100 \mathrm{mV}$ (deactivation of the SV; the so-called tail currents). The arrow indicates the threshold for the SV channel voltage activation (i.e., first test voltage, after which some tail current was observed); (B,C) Activation curves for salt-sensitive Q5206 and salt-tolerant Q16 varieties. Mean number of open SV channels (calculated as a tail current at $-100 \mathrm{mV}$, divided by the single channel current at this potential) at tonoplast unit surface unit $\left(1 \mathrm{pF} \sim 100 \mu \mathrm{m}^{2}\right)$ is shown as a function of test voltage. Solid lines are the best fits to the pair of Boltzmann distributions. Data are mean \pm SE $(n=6-13)$. Plants were grown either under control $(50 \mathrm{mM} \mathrm{NaCl})$ or saline $(400 \mathrm{mM} \mathrm{NaCl})$ conditions. Recordings were made under symmetric $100 \mathrm{mM} \mathrm{KCl}$ conditions. One millimolar $\mathrm{Ca}^{2+}$ was added to the cytosolic side to activate SV and inhibit FV currents.

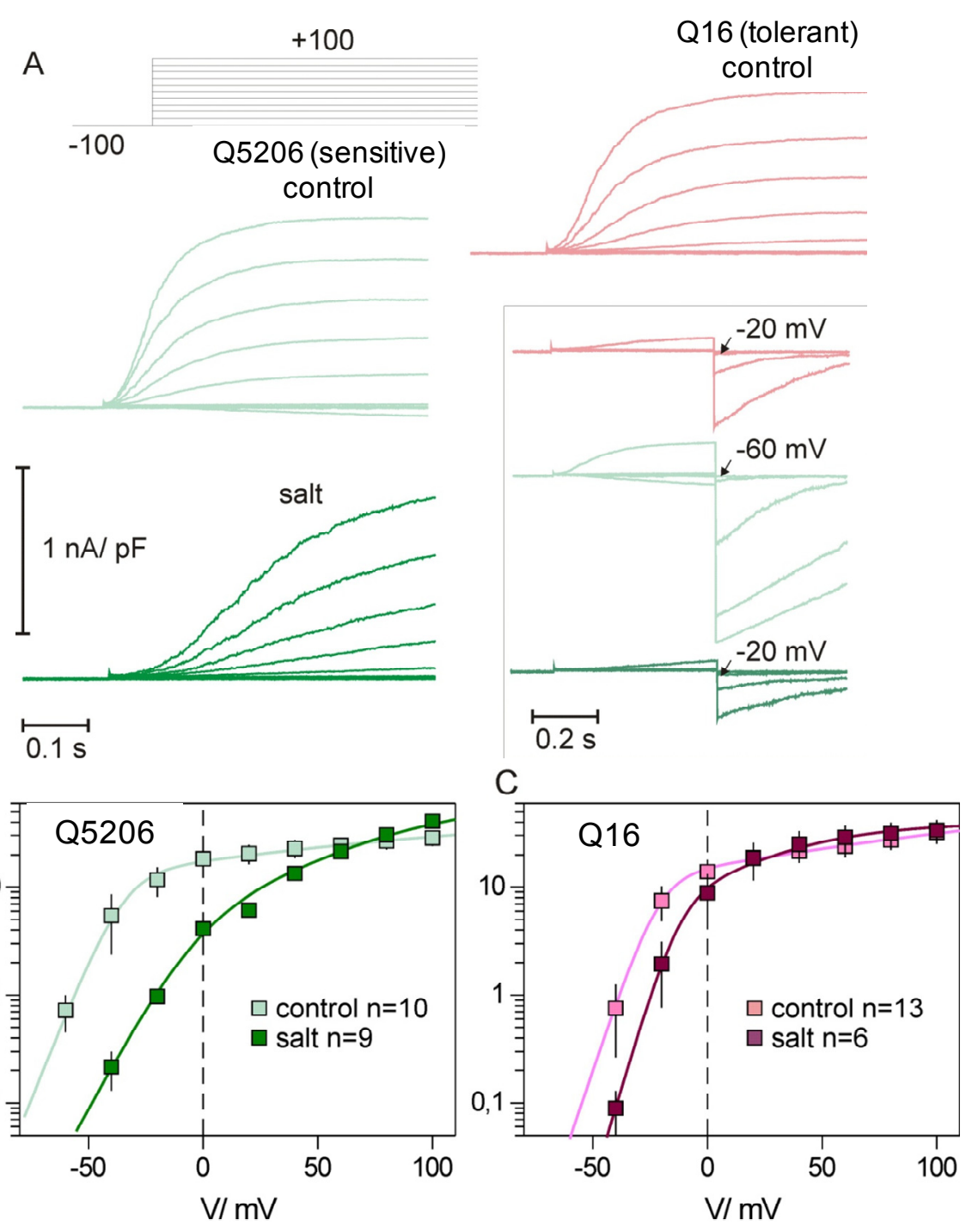




\section{Discussion}

Salinity tolerance in plants is a complex trait, both physiologically and genetically [1]. Multiple mechanisms are involved, and their relative contribution may differ dramatically depending on the developmental stage of the plant, severity of the salinity stress and any confounding effects of other environmental factors. Indeed, while a plant's ability to control stomata to maintain the optimal balance between water availability and leaf transpiration rate in saline soils may be critical for advanced plants [39], this trait is of no importance at germination or the coleoptile stage (when stomatal transpiration is almost non-existent). Another example is $\mathrm{Na}^{+}$exclusion from uptake. In plant roots, this exclusion is mediated by a SOS1-like $\mathrm{Na}^{+} / \mathrm{H}^{+}$exchanger [26], fuelled by the plasma membrane $\mathrm{H}^{+}$-ATPase. If salinity problems coincides with flooding (a situation often found in nature; [40]), the root's ability to exclude $\mathrm{Na}^{+}$will be compromised by the lack of oxygen required to maintain a high $\mathrm{H}^{+}$-ATPase activity. Under these conditions, tissue tolerance mechanisms, such as ROS scavenging or vacuolar $\mathrm{Na}^{+}$sequestration, may become much more important. Consequently, we should accept the fact that there is no such thing as a "silver bullet" that can resolve salinity problems; manipulating only one trait (gene) is not likely to result in any significant improvements. Salinity tolerance problems will only be resolved when several key traits are combined in a complementary manner. Nonetheless, the introgression of the single Nax2 gene has been shown to improve the grain yield in durum wheat by $20 \%$ under saline conditions [41], suggesting that some traits are of greater importance than others are. The nature of these traits may be learned from halophytes, by definition, the most salt tolerant species.

Our previous studies on quinoa have identified several whole-plant physiological traits that could be essential for the high salinity tolerance in this species $[6,18,20,21,42]$. Here, we extend this list by adding several intracellular mechanisms that contribute to the genetic variability in salinity tolerance. These mechanisms include: (i) a higher rate of $\mathrm{Na}^{+}$exclusion from the leaf mesophyll; (ii) maintenance of low cytosolic $\mathrm{Na}^{+}$levels; (iii) better $\mathrm{K}^{+}$retention in the leaf mesophyll; (iv) more active $\mathrm{H}^{+}$pumping, enabling the restoration of membrane potentials in mesophyll cells; and (v) an ability to reduce the activity of SV and FV channels under saline conditions (Table 1).

Table 1. Intracellular traits differentiating salinity tolerance between quinoa genotypes.

\begin{tabular}{|c|c|c|}
\hline Trait & Q5206 (sensitive) & Q16 (tolerant) \\
\hline $\mathrm{Na}^{+}$uptake into mesophyll & High & Low \\
\hline Active $\mathrm{Na}^{+}$exclusion & Low & High \\
\hline Cytosolic $\mathrm{Na}^{+}$level & High & Low \\
\hline $\mathrm{K}^{+}$retention in leaf mesophyll & Low & High \\
\hline Ability to restore MP & Low & High \\
\hline FV activity ${ }^{a}$ & High & Low \\
\hline SV density ${ }^{b}$ & High & Low \\
\hline
\end{tabular}

${ }^{a}$ This reflects the FV activity in intact vacuoles, both in control plants and those subjected to salt stress. When the vacuolar lumen is perfused with an artificial pipette solution, the difference in the FV activity between them tends to decrease; ${ }^{b}$ This is true for plants grown under control conditions. Salt adaptation causes a shift in the threshold for SV activation in the salt-sensitive Q5206; its activity under these conditions approaches that of the salt-tolerant Q16. 
These traits, which differ between sensitive and tolerant quinoa genotypes, are well orchestrated, forming several "lines of defence" in mesophyll cells. First, the tolerant genotype has a smaller net $\mathrm{Na}^{+}$ uptake into the mesophyll (Figure 2A) and has a superior capacity to extrude accumulated $\mathrm{Na}^{+}$ (Figure 2B). We have previously shown that in wheat and Arabidopsis, such a net $\mathrm{Na}^{+}$efflux is attributed to the activity of SOS1-like proteins in the plant root epidermis [43]. We suggest that a similar scenario occurs in the quinoa mesophyll. Indeed, functional SOS1 analogues have been reported in quinoa [44,45], and saline treatment $(450 \mathrm{mM} \mathrm{NaCl})$ has been shown to cause an up-regulation of SOS1 in quinoa leaves [44].

At the same time, the tolerant quinoa genotype had much a better ability to retain $\mathrm{K}^{+}$in the leaf mesophyll (Figure 2C). Maintenance of a high cytosolic $\mathrm{K}^{+}$is not only important for the activity of a large number of cytosolic enzymes [46], but is also essential for suppressing the activity of caspase-like proteases and endonucleases in plant cells [47-49]. If depletion in the cytosolic $\mathrm{K}^{+}$pool cannot be prevented, protein catabolism takes place, resulting in programmed cell death (PCD) $[48,50]$. In Arabidopsis and barley, depolarisation-activating outward rectifying $\mathrm{K}^{+}$channels are the main route for $\mathrm{K}^{+}$efflux under saline conditions [32]. As such, restoring membrane potential by more active $\mathrm{H}^{+}$ pumping is a possible way of controlling such a leak, so preventing stress-induced PCD. This seems to be the case for the quinoa mesophyll. A sustained net $\mathrm{H}^{+}$efflux was induced in the salt-tolerant Q16 genotype by $\mathrm{NaCl}$ treatment (Figure 2D), while such activation was very short-lived in the sensitive Q5206.

Together, better $\mathrm{Na}^{+}$exclusion to the apoplast (Figure 2B) and a higher $\mathrm{K}^{+}$retention in the cytosol (Figure 2C) will ensure a more optimal cytosolic $\mathrm{K}^{+} / \mathrm{Na}^{+}$ratio, a key feature conferring salinity tolerance in plants [51].

The tolerant Q16 genotype was capable of maintaining much lower cytosolic $\mathrm{Na}^{+}$levels (Figure 3). Two major mechanisms contributed to this feature. First, as discussed above, the Q16 genotype had much better ability to actively extrude $\mathrm{Na}^{+}$(Figure 2B). Second, the activities of the $\mathrm{Na}^{+}$-permeable tonoplast SV and FV channels were much lower in the tolerant genotype (Figures 5-9). Earlier, we showed [25] that quinoa's tonoplast SV and FV activity is strongly affected by the amount of $\mathrm{Na}^{+}$ accumulated in leaf tissue. Both FV and SV channel activity were several fold lower in old leaves (accumulating more $\mathrm{Na}^{+}$) compared to young ones. This reduction was interpreted as a need to prevent $\mathrm{Na}^{+}$leaking back into the cytosol after its sequestration to the vacuole by a NHX-like $\mathrm{Na}^{+} / \mathrm{H}^{+}$ exchanger [22]. Thus, it appears that this ability to control tonoplast channel activity is not only stress-inducible, but is also genetically controlled and contributes to the differential salinity tolerance between genotypes.

Interestingly, vacuolar $\mathrm{Na}^{+}$concentrations were higher in the sensitive Q5206 than in the tolerant Q16 genotype, both in control and in salt-treated plants (Figure 3). This may be due to a better ability to control $\mathrm{Na}^{+}$delivery to the shoot in the Q16 genotype, so the plant has less $\mathrm{Na}^{+}$in the shoot. Nonetheless, both genotypes are classified as halophytes, so can sequester substantial amounts of $\mathrm{Na}^{+}$ in their vacuoles. In this context, the higher $\mathrm{Na}^{+}$sequestration ability of Q5206 may be a compensatory trait accounting for its poorer $\mathrm{Na}^{+}$exclusion ability.

One more result should be commented upon. Both FV (Figure 8) and SV (Figure 9) channel activity was significantly reduced in plants grown under high $(400 \mathrm{mM} \mathrm{NaCl})$ salinity. It appears that in a tolerant genotype, the tonoplast channel activity is intrinsically lower, while in sensitive genotypes, this 
reduction is stress-inducible. This pattern is reminiscent of that related to the expression of tonoplast $\mathrm{NHX} \mathrm{Na} / \mathrm{H}^{+}$antiporters. These antiporters are constitutive in halophytes [10,24,52], but are induced by $\mathrm{NaCl}$ in glycophytes [53-55]. Thus, any difference between plant performance will be maximal at the onset of salt stress, because stress-inducible down-regulation of FV and SV channels in salt-sensitive genotypes may take some time. It remains to be answered as to whether these changes in $\mathrm{SV}$ and FV activity originate from changes at the transcript level (expression patterns) of these transporters under saline conditions, post-translational regulation or the existence of alternative splicing forms or whether the observed difference is attributed to channel regulation by some cytosolic or luminal compound(s). The latter seems to be true for FV channels. These are likely to be controlled by some, as yet unknown, luminal factor, which can be washed out from the vacuole. This would reduce the difference in FV activity between the salt-sensitive and salt-tolerant varieties (Figures 6 and 8). The nature of this factor, which controls the run-up of the whole vacuole FV activity under patch-clamp conditions, as well as of those that control the threshold for SV channels activation under salt stress, has to be addressed in future experiments.

\section{Experimental Section}

\subsection{Plant Material and Growth Conditions}

Two quinoa (Chenopodium quinoa Willd.) varieties contrasting in salinity tolerance [18,21] were used in this study. A relatively salt-sensitive variety Q5206 (also known as Titicaca) is an early maturing, day-length neutral cultivar that has been bred and selected for North European conditions at the Faculty of Sciences, Univ. Copenhagen, Denmark, from material originating from crosses between southern coastal Chilean and Peruvian altiplano lines, followed by the mass selection. A more salt-tolerant variety Q16 (also known as Huallata) is a traditional short day cultivar of the real type from the southern Bolivian Altiplano $\left(20^{\circ} 28^{\prime} \mathrm{S}, 66^{\circ} 50^{\prime} \mathrm{W}, 3650 \mathrm{~m}\right.$ above sea level). Plants were grown from seed under controlled greenhouse conditions (temperature between 19 and $26{ }^{\circ} \mathrm{C}$; day length, $12 \mathrm{~h}$; average humidity $\sim 65 \%$ ) at the University of Tasmania between April 2012 and November 2012. Plants were grown in $2 \mathrm{~L}$ plastic pots using a standard potting mix (70\% composted pine bark; $20 \%$ coarse sand; $10 \%$ sphagnum peat; Limil at $1.8 \mathrm{~kg} / \mathrm{m}^{3}$, dolomite at $1.8 \mathrm{~kg} / \mathrm{m}^{3}$ ). The plant nutrient balance was maintained by adding the slow release Osmocote Plus ${ }^{\mathrm{TM}}$ fertilizer (at $6 \mathrm{~kg} / \mathrm{m}^{3}$ ), plus ferrous sulphate (at $500 \mathrm{~g} / \mathrm{m}^{3}$ ). Once plants were 3-weeks old, salinity stress was given using $400 \mathrm{mM}$ $\mathrm{NaCl}$ for irrigation. Control plants were irrigated with $50 \mathrm{mM} \mathrm{NaCl}$ (a concentration found to be stimulating for quinoa growth). Salt treatment was provided as $40 \mathrm{mM} /$ day increments. The final concentration of $400 \mathrm{mM}$ was reached at day 10 and maintained for a further seven weeks.

\subsection{Vacuole Isolation and Patch-Clamp Electrophysiology}

Vacuoles were mechanically isolated from mesophyll protoplasts obtained by enzymatic digestion as described in our recent work [25]. The enzyme solution contained 2\% $(w / v)$ cellulose (Yakult Honsha, Tokyo, Japan), 1.2\% (w/v) cellulysin (Biosciences Inc., San Diego, CA, USA), 0.1\% (w/v) pectolyase, $0.1 \%(w / v)$ bovine serum albumin, $10 \mathrm{mM} \mathrm{KCl}, 10 \mathrm{mM} \mathrm{CaCl}_{2}$ and $2 \mathrm{mM} \mathrm{MgCl}_{2}, \mathrm{pH}$ 5.7, adjusted with $2 \mathrm{mM}$ MES. Solution osmolality was adjusted to 750-800 mOsm for control and to 
1700-1800 mOsm for salt-grown plants using sorbitol. Once released by plasmolysis, protoplasts were washed and kept in a "storage solution" (100 mM KCl; $0.5 \mathrm{mM}$ EDTA; $10 \mathrm{mM}$ HEPES; $10 \mathrm{mM}$ glucose; $10 \mathrm{mM}$ sucrose; $\mathrm{pH}$ 7.4; osmolality 500-570 mOsm for control or 1450-1500 mOsm for salt-grown leaves) on ice. Current measurements were performed using an Axopatch 200B Integrating Patch-clamp amplifier (Axon Instruments, Foster City, CA, USA), as described elsewhere [25]. The standard pipette solution contained (in $\mathrm{mM}$ ): $100 \mathrm{KCl}, 5$ EGTA and $10 \mathrm{MES}-\mathrm{KOH}$ (pH 6). Bath solution for FV currents contained (in mM): $100 \mathrm{KCl}, 0.5$ EDTA, 10 HEPES-KOH (pH 7.4). To inhibit FV and activate SV currents, 0.5 EDTA was substituted with $1 \mathrm{CaCl}_{2}$. Specific voltage protocols are given directly on the figures.

\subsection{Intracellular $\mathrm{Na}^{+}$Measurements}

The cytosolic and vacuolar $\mathrm{Na}^{+}$content was measured using fluorescent $\mathrm{Na}^{+}$dye (CoroNa Green acetoxymethyl ester; Invitrogen, Carlsbad, CA, USA), as described in our previous work [25]. Quinoa plants were grown in a glasshouse, as described above. The youngest fully expanded leaves were collected; abaxial epidermis was peeled off with a pair of fine forceps and peeled leaf segments were incubated in a buffer solution containing CoroNa Green in the dark for $1 \mathrm{~h}$ before measurement. Confocal imaging was conducted on a Leica inverted microscope fitted with a TCS SPII confocal head (Leica Microsystems, Heidelberg, Germany), as described in [25]. Images were analysed with LAS AF software (Leica Microsystems, Heidelberg, Germany) and Image J software (NIH, USA) to calculate vacuole or cytosol fluorescence corrected for the background [56]. Results are reported per surface area. This represents $\mathrm{Na}^{+}$concentrations in an appropriate compartment expressed in arbitrary units.

\subsection{Non-Invasive Ion Flux Measurements}

Net fluxes of $\mathrm{K}^{+}, \mathrm{Na}^{+}$and $\mathrm{H}^{+}$were measured using non-invasive microelectrode ion flux estimation (the MIFE) technique (Univ. Tasmania, Hobart, Tasmania), essentially as described in our previous publications [14,27,42,57]. Commercially available $\mathrm{K}^{+}$(catalogue No 60031) and $\mathrm{H}^{+}$(catalogue No 95297) LIX were used (both from Sigma-Aldrich, St. Luis, MO, USA). For $\mathrm{Na}^{+}$measurements, an improved calixarene-based $\mathrm{Na}^{+}$cocktail was used (see [58] for details). The principle of the MIFE measurements and all details on microelectrode fabrication and calibration are available in previous publications (e.g., [57]). In brief, glass microelectrodes were pulled from non-filamentous glass capillaries, salinized with tributylchlorosilane (Fluka Chemicals 90796, Busch, Switzerland) and filled with the appropriate ion-selective cocktail. Electrodes were calibrated in a set of $\mathrm{pH}, \mathrm{K}^{+}$or $\mathrm{Na}^{+}$ standards, then used for measurements. One youngest, but fully mature leaf was harvested and brought into laboratory in a sealed plastic bag. The abaxial leaf epidermis was removed using fine tweezers, and leaf segments of approximately $5 \times 8 \mathrm{~mm}$ were cut and left floating (peeled side down) overnight in the Basic Salt Medium (BSM) containing $0.5 \mathrm{mM} \mathrm{KCl}, 0.1 \mathrm{mM} \mathrm{CaCl}_{2}, \mathrm{pH} 6.0$ (not buffered). To eliminate possible confounding wounding effects, measurements were conducted next day (see [27] for all methodological aspects). One hour prior to measurement, leaf segments were immobilised in the measuring chamber and electrode tips were positioned $30 \mu \mathrm{m}$ above the leaf surface, with their tips aligned and separated by 1-3 $\mu \mathrm{m}$. During measurement, electrodes were moved back and forward in a square-wave manner by a computerised stepper motor between two positions, 80 and $30 \mu \mathrm{m}$ above the 
leaf surface, with $0.1 \mathrm{~Hz}$ frequency. Net ion fluxes were calculated from the measured differences in electrochemical potential for each ion between these two positions as described elsewhere [57].

\section{Conclusions}

Multiple mechanisms may contribute towards genotypic differences in salinity tolerance in quinoa. These include: (i) a higher rate of $\mathrm{Na}^{+}$exclusion from the leaf mesophyll; (ii) maintenance of low cytosolic $\mathrm{Na}^{+}$levels; (iii) a better $\mathrm{K}^{+}$retention in the leaf mesophyll; (iv) a higher rate of $\mathrm{H}^{+}$extrusion that contributes towards the restoration of the membrane potential in mesophyll cells; and (v) the ability to reduce the activity of SV and FV channels under saline conditions. These mechanisms appear to be highly orchestrated, thus enabling a remarkable overall salinity tolerance in quinoa species.

\section{Acknowledgements}

This work was supported by the Australian Research Council Discovery (DP1094663) and Linkage (LP100200456) grants to Sergey Shabala. Tracey Cuin is thanked for her assistance in proof reading this MS.

\section{Conflict of Interest}

The authors declare no conflict of interest.

\section{References}

1. Flowers, T.J. Improving crop salt tolerance. J. Exp. Bot. 2004, 55, 307-319.

2. Flowers, T.J.; Galal, H.K.; Bromham, L. Evolution of halophytes: Multiple origins of salt tolerance in land plants. Funct. Plant Biol. 2010, 37, 604-612.

3. Shabala, S.; Mackay, A. Ion transport in halophytes. Adv. Bot. Res. 2011, 57, 151-199.

4. Neales, T.F.; Sharkey, P.J. Effect of salinity on growth and on mineral and organic constituents of the halophyte Disphyma ustrale (Soland.) black. Austr. J. Plant Physiol. 1981, 8, 165-179.

5. Storey, R.; Wyn Jones, R.G. Responses of Atriplex spongiosa and Suaeda monoica to salinity. Plant Physiol. 1979, 63, 156-162.

6. Hariadi, Y.; Marandon, K.; Tian, Y.; Jacobsen, S.E.; Shabala, S. Ionic and osmotic relations in quinoa (Chenopodium quinoa Willd.) plants grown at various salinity levels. J. Exp. Bot. 2011, 62, 185-193.

7. Redondo-Gomez, S.; Mateos-Naranjo, E.; Davy, A.J.; Fernandez-Munoz, F.; Castellanos, E.M.; Luque, T.; Figueroa, M.E. Growth and photosynthetic responses to salinity of the salt-marsh shrub Atriplex portulacoides. Ann. Bot. 2007, 100, 555-563.

8. Maas, E.V.; Hoffman, G.J. Crop salt tolerance assessment. ASCE J. Irrig. Drain. Div. 1977, 103, $115-134$.

9. Cuin, T.A.; Tian, Y.; Betts, S.A.; Chalmandrier, R.; Shabala, S. Ionic relations and osmotic adjustment in durum and bread wheat under saline conditions. Funct. Plant Biol. 2009, 36, 1110-1119. 
10. Glenn, E.P.; Brown, J.J.; Blumwald, E. Salt tolerance and crop potential of halophytes. Crit. Rev. Plant Sci. 1999, 18, 227-255.

11. Flowers, T.J.; Colmer, T.D. Salinity tolerance in halophytes. New Phytol. 2008, 179, 945-963.

12. Greenway, H.; Munns, R. Mechanisms of salt tolerance in nonhalophytes. Annu. Rev. Plant Physiol. 1980, 31, 149-190.

13. Colmer, T.D.; Flowers, T.J.; Munns, R. Use of wild relatives to improve salt tolerance in wheat. J. Exp. Bot. 2006, 57, 1059-1078.

14. Chen, Z.H.; Zhou, M.X.; Newman, I.A.; Mendham, N.J.; Zhang, G.P.; Shabala, S. Potassium and sodium relations in salinised barley tissues as a basis of differential salt tolerance. Funct. Plant Biol. 2007, 34, 150-162.

15. Shabala, S.; Cuin, T.A.; Pang, J.Y.; Percey, W.; Chen, Z.H.; Conn, S.; Eing, C.; Wegner, L.H. Xylem ionic relations and salinity tolerance in barley. Plant J. 2010, 61, 839-853.

16. Mian, A.; Oomen, R.; Isayenkov, S.; Sentenac, H.; Maathuis, F.J.M.; Very, A.A. Over-expression of an $\mathrm{Na}^{+}$- and $\mathrm{K}^{+}$-permeable HKT transporter in barley improves salt tolerance. Plant J. 2011, 68, 468-479.

17. Repo-Carrasco, R.; Espinoza, C.; Jacobsen, S.E. Nutritional value and use of the Andean crops quinoa (Chenopodium quinoa) and kaniwa (Chenopodium pallidicaule). Food Rev. Int. 2003, 19, 179-189.

18. Adolf, V.I.; Jacobsen, S.-E.; Shabala, S. Salt tolerance mechanisms in quinoa (Chenopodium quinoa Willd.). Environ. Exp. Bot. 2013, in press.

19. Jacobsen, S.E.; Mujica, A.; Jensen, C.R. The resistance of quinoa (Chenopodium quinoa Willd.) to adverse abiotic factors. Food Rev. Int. 2003, 19, 99-109.

20. Adolf, V.I.; Shabala, S.; Andersen, M.N.; Razzaghi, F.; Jacobsen, S.E. Varietal differences of quinoa's tolerance to saline conditions. Plant Soil 2012, 357, 117-129.

21. Shabala, S.; Hariadi, Y.; Jacobsen, S.-E. Genotypic difference in salinity tolerance in quinoa is determined by differential control of xylem $\mathrm{Na}^{+}$loading and stomatal density. J. Plant Physiol. 2013, doi:10.1016/j.jplph.2013.01.014.

22. Blumwald, E.; Aharon, G.S.; Apse, M.P. Sodium transport in plant cells. Biochim. Biophys. Acta Biomembr. 2000, 1465, 140-151.

23. Pantoja, O.; Dainty, J.; Blumwald, E. Ion channels in vacuoles from halophytes and glycophytes. FEBS Lett. 1989, 255, 92-96.

24. Barkla, B.J.; Zingarelli, L.; Blumwald, E.; Smith, J.A.C. Tonoplast $\mathrm{Na}^{+} / \mathrm{H}^{+}$antiport activity and its energization by the vacuolar $\mathrm{H}^{+}$-ATPase in the halophytic plant Mesembryanthemum crystallinum L. Plant Physiol. 1995, 109, 549-556.

25. Bonales-Alatorre, E.; Shabala, S.; Chen, Z.H.; Pottosin, I. Reduced tonoplast FV and SV channels activity is essential for conferring salinity tolerance in a facultative halophyte, Chenopodium quinoa. Plant Physiol. 2013, in press.

26. Shi, H.Z.; Ishitani, M.; Kim, C.S.; Zhi, J.K. The Arabidopsis thaliana salt tolerance gene SOS1 encodes a putative $\mathrm{Na}^{+} / \mathrm{H}^{+}$antiporter. Proc. Natl. Acad. Sci. USA 2000, 97, 6896-6901.

27. Shabala, S. Ionic and osmotic components of salt stress specifically modulate net ion fluxes from bean leaf mesophyll. Plant Cell Environ. 2000, 23, 825-837. 
28. Shabala, S.; Demidchik, V.; Shabala, L.; Cuin, T.A.; Smith, S.J.; Miller, A.J.; Davies, J.M.; Newman, I.A. Extracellular $\mathrm{Ca}^{2+}$ ameliorates $\mathrm{NaCl}$-induced $\mathrm{K}^{+}$loss from Arabidopsis root and leaf cells by controlling plasma membrane $\mathrm{K}^{+}$-permeable channels. Plant Physiol. 2006, 141, $1653-1665$.

29. Shabala, S.; Shabala, L.; van Volkenburgh, E.; Newman, I. Effect of divalent cations on ion fluxes and leaf photochemistry in salinized barley leaves. J. Exp. Bot. 2005, 56, 1369-1378.

30. Smethurst, C.F.; Rix, K.; Garnett, T.; Auricht, G.; Bayart, A.; Lane, P.; Wilson, S.J.; Shabala, S. Multiple traits associated with salt tolerance in lucerne: Revealing the underlying cellular mechanisms. Funct. Plant Biol. 2008, 35, 640-650.

31. Palmgren, M.G.; Nissen, P. P-type ATPases. Annu. Rev. Biophys. 2011, 40, 243-266.

32. Shabala, S.; Cuin, T.A. Potassium transport and plant salt tolerance. Physiol. Plant. 2008, 133, 651-669.

33. Very, A.A.; Sentenac, H. Cation channels in the Arabidopsis plasma membrane. Trends Plant Sci. 2002, 7, 168-175.

34. Tikhonova, L.I.; Pottosin, I.I.; Dietz, K.J.; Schönknecht, G. Fast-activating cation channel in barley mesophyll vacuoles. Inhibition by calcium. Plant J. 1997, 11, 1059-1070.

35. Brüggemann, L.I.; Pottosin, I.I.; Schönknecht, G. Cytoplasmic polyamines block the fast-activating vacuolar cation channel. Plant J. 1998, 16, 101-105.

36. Pottosin, I.I.; Martínez-Estévez, M. Regulation of the fast vacuolar channel by cytosolic and vacuolar potassium. Biophys. J. 2003, 84, 977-986.

37. Pottosin, I.I.; Dobrovinskaya, O.R.; Muñiz, J. Conduction of monovalent and divalent cations in the slow vacuolar channel. J. Membr. Biol. 2001, 181, 55-65.

38. Pérez, V.; Wherrett, T.; Shabala, S.; Muñiz, J.; Dobrovinskaya, O.; Pottosin, I. Homeostatic control of slow vacuolar channels by luminal cations and evaluation of the channel-mediated tonoplast $\mathrm{Ca}^{2+}$ fluxes in situ. J. Exp. Bot. 2008, 59, 3845-3855.

39. Munns, R. Comparative physiology of salt and water stress. Plant Cell Environ. 2002, 25, 239-250.

40. Colmer, T.D.; Flowers, T.J. Flooding tolerance in halophytes. New Phytol. 2008, 179, 964-974.

41. Munns, R.; James, R.A.; Xu, B.; Athman, A.; Conn, S.J.; Jordans, C.; Byrt, C.S.; Hare, R.A.; Tyerman, S.D.; Tester, M.; et al. Wheat grain yield on saline soils is improved by an ancestral $\mathrm{Na}^{+}$transporter gene. Nature Biotechnol. 2012, 30, 360-364.

42. Razzaghi, F.; Ahmadi, S.H.; Adolf, V.I.; Jensen, C.R.; Jacobsen, S.E.; Andersen, M.N. Water relations and transpiration of quinoa (Chenopodium quinoa Willd.) under salinity and soil drying. J. Agron. Crop Sci. 2011, 197, 348-360.

43. Cuin, T.A.; Bose, J.; Stefano, G.; Jha, D.; Tester, M.; Mancuso, S.; Shabala, S. Assessing the role of root plasma membrane and tonoplast $\mathrm{Na}^{+} / \mathrm{H}^{+}$exchangers in salinity tolerance in wheat: In planta quantification methods. Plant Cell Environ. 2011, 34, 947-961.

44. Maughan, P.J.; Turner, T.B.; Coleman, C.E.; Elzinga, D.B.; Jellen, E.N.; Morales, J.A.; Udall, J.A.; Fairbanks, D.J.; Bonifacio, A. Characterization of Salt Overly Sensitive 1 (SOS 1) gene homologs in quinoa (Chenopodium quinoa Wilid.). Genome 2009, 52, 647-657. 
45. Ruiz-Carrasco, K.; Antognoni, F.; Coulibaly, A.K.; Lizardi, S.; Covarrubias, A.; Martinez, E.A.; Molina-Montenegro, M.A.; Biondi, S.; Zurita-Silva, A. Variation in salinity tolerance of four lowland genotypes of quinoa (Chenopodium quinoa Willd.) as assessed by growth, physiological traits, and sodium transporter gene expression. Plant Physiol. Biochem. 2011, 49, 1333-1341.

46. Dreyer, I.; Uozumi, N. Potassium channels in plant cells. FEBS J. 2011, 278, 4293-4303.

47. Affenzeller, M.J.; Darehshouri, A.; Andosch, A.; Lutz, C.; Lutz-Meindl, U. Salt stress-induced cell death in the unicellular green alga Micrasterias denticulata. J. Exp. Bot. 2009, 60, 939-954.

48. Demidchik, V.; Cuin, T.A.; Svistunenko, D.; Smith, S.J.; Miller, A.J.; Shabala, S.; Sokolik, A.; Yurin, V. Arabidopsis root $\mathrm{K}^{+}$-efflux conductance activated by hydroxyl radicals: Single-channel properties, genetic basis and involvement in stress-induced cell death. J. Cell Sci. 2010, 123, $1468-1479$.

49. Wang, J.; Li, X.R.; Liu, Y.B.; Zhao, X.; Chen, C.Y.; Tian, F. MEK/ERK inhibitor U0126 enhanced salt stress-induced programmed cell death in Thellungiella halophila suspension-cultured cells. Plant Growth Regul. 2011, 63, 207-216.

50. Shabala, S. Salinity and programmed cell death: Unravelling mechanisms for ion specific signalling. J. Exp. Bot. 2009, 60, 709-711.

51. Maathuis, F.J.M.; Amtmann, A. $\mathrm{K}^{+}$nutrition and $\mathrm{Na}^{+}$toxicity: The basis of cellular $\mathrm{K}^{+} / \mathrm{Na}^{+}$ratios. Ann. Bot. 1999, 84, 123-133.

52. Matoh, T.; Ishikawa, T.; Takahashi, E. Collapse of ATP-induced ph gradient by sodium ions in microsomal membrane vesicles prepared from Atriplex gmelini leaves-Possibility of $\mathrm{Na}^{+} / \mathrm{H}^{+}$ antiport. Plant Physiol. 1989, 89, 180-183.

53. Garbarino, J.; Dupont, F.M. $\mathrm{NaCl}$ induces a $\mathrm{Na}^{+} / \mathrm{H}^{+}$antiport in tonoplast vesicles from barley roots. Plant Physiol. 1988, 86, 231-236.

54. Yokoi, S.; Quintero, F.J.; Cubero, B.; Ruiz, M.T.; Bressan, R.A.; Hasegawa, P.M.; Pardo, J.M. Differential expression and function of Arabidopsis thaliana $\mathrm{NHX} \mathrm{Na} / \mathrm{H}^{+}$antiporters in the salt stress response. Plant J. 2002, 30, 529-539.

55. Adler, G.; Blumwald, E.; Bar-Zvi, D. The sugar beet gene encoding the sodium/proton exchanger 1 (BvNHX1) is regulated by a MYB transcription factor. Planta 2010, 232, 187-195.

56. Burgess, A.; Vigneron, S.; Brioudes, E.; Labbé, J.-C.; Lorca, T.; Castro, A. Loss of human Greatwall results in $\mathrm{G} 2$ arrest and multiple mitotic defects due to deregulation of the cyclin B-Cdc2/PP2A balance. Proc. Natl. Acad. Sci. USA 2010, 107, 12564-12569.

57. Shabala, L.; Ross, T.; McMeekin, T.; Shabala, S. Non-invasive microelectrode ion flux measurements to study adaptive responses of microorganisms to the environment. FEMS Microbiol. Rev. 2006, 30, 472-486.

58. Jayakannan, M.; Babourina, O.; Rengel, Z. Improved measurements of $\mathrm{Na}^{+}$fluxes in plants using calixarene-based microelectrodes. J. Plant Physiol. 2011, 168, 1045-1051.

(C) 2013 by the authors; licensee MDPI, Basel, Switzerland. This article is an open access article distributed under the terms and conditions of the Creative Commons Attribution license (http://creativecommons.org/licenses/by/3.0/). 